\title{
Quality and inequality
}

\section{DOI: 10.7861/fhj.ed.8.1.1}

Welcome to this issue of the Future Healthcare Journal (FHJ). I usually start my editorial by saying how important the issue's theme is, but it is hard to underestimate the importance of tackling inequality in our society and in our healthcare system. Indeed, it was a particular focus for Donal O'Donoghue, our Royal College of Physicians' registrar, who so tragically succumbed to COVID-19 earlier this year. Our efforts to improve future healthcare through this publication are dedicated to him and so many other victims of this pandemic.

I pay particular thanks to our board member Dr Mohsin Choudry who took on the role of commissioning and collating this issue. The result is exceptional. Of course, such projects always need a team of people and Mohsin was greatly supported by Dan Sumners at the college, as well as external support from Dr Michael Dixon, and from Prof Carol Brayne and Dr Farhang Tahzib both from the Faculty of Public Health.

We are especially grateful that HRH The Prince of Wales has shared his passion and reflections on the theme. Such influential backing will undoubtedly help progress.

Overall, the range and spectrum of themed articles make these important, if not mandatory, reading for anyone in the healthcare sector. All are free to access so please disseminate through your contacts by word of mouth, email and social media.

COVID-19 has highlighted the issue of inequality, from susceptibility through to treatment and preventive strategies. These will hopefully be drivers of progress. But I am concerned that the image of the NHS in recent months has been of intensive care units, ventilators and extracorporeal membrane oxygenation (ECMO). These are some of the highest technology care that the NHS can offer, and my thanks, admiration and respect go to all those providing this care. However, this is the top of a pyramid. It is likely that work at the base, in terms of prevention, public health and primary care are where the greatest reductions in health outcome variation will be achieved. This must not be forgotten as we look to plan and resource the post-COVID health service.

The paper from Tom Wingfield and his team in Liverpool 'What do people hospitalised with COVID-19 think about their care?' is worth highlighting because I was particularly struck by the usefulness of the poster appended to the paper (their Fig 3).' It is titled 'COVID-19: How can we improve the patient experience?' and provides an excellent single sheet summary of how to offer best care.

Another aspect of the pandemic is making difficult prioritisation choices. Rowan Wathes and colleagues from Imperial College London report on a model to try and prioritise rationally across medical and surgical specialties, based on clinical priority, clinical harm and patient vulnerability. ${ }^{2}$ We have always rationed in the NHS. The National Institute for Health and Care Excellence and the Cancer Drugs Fund are just two mechanisms used to allocate care. But I hope the experience of the last year will make the debate more open and constructive going forward.

Having two excellent physician associates on our editorial board means that we can truly represent their part in the college and their role in the provision of healthcare. The paper by Ria Agarwal and Julie Hoskin 'Clinical supervision of physician associates (PAs) in primary care: who, what and how is it done?' provides insight into the important parameters and ground rules for effective PA supervision. ${ }^{3}$

These articles have been distilled from nearly 300 high-quality submissions in 2020, a three-fold increase on the previous year. A reminder to all our readers that this paper issue is just a small part of the material on offer through the FHJ. Please go to our website for the COVID-19 subject collection, 'e'publications on the complete spectrum of future healthcare, education and quality improvement (www.rcpjournals.org). Many of you are clearly doing so as downloads have more than doubled in the last year. In addition, do join us for our regular Twitter debates for real time discussion of key topics and papers (@FutureHealth]) and listen to our podcasts (https://rcppodopia.buzzsprout.com). We are actively exploring the option that future editions of $F H$ J will be exclusively online. Many of you will have opted out of print already. On this topic, as with the content, your feedback is always appreciated.

I do hope the articles in this issue provide a little relief, challenge and inspiration. I suspect you share with me emotional and physical fatigue. We do have hope and we must be thankful to the exceptional skill and dedication of those pursuing research at breath-taking pace into the pandemic and its defeat. The theme of our next issue is therefore appropriately 'Research'. Meanwhile, I hope you enjoy this issue of the Future Healthcare Journal.

\section{Dr Kevin Fox Editor-in-chief}

\section{References}

1 Wu MS, Watson R, Hayat F et al. What do people hospitalised with COVID-19 think about their care? Results of a satisfaction survey during the first wave of COVID-19 in Liverpool. FHJ 2021;8:e70-5.

2 Wathes R, Malhotra K, Flott K, Nath A, Urch C. Towards a standardised method of patient prioritisation that accounts for clinical harm. FHJ 2021:8:e42-6.

3 Agarwal R, Hoskin J. Clinical supervision of physician associates (PAs) in primary care: who, what and how is it done? FHJ 2021;8:57-61.

\section{Members of the editorial board}

Suzie Bailey

Kate Bascombe

Rodger Charlton

Laura Chenevert

Mohsin Choudry

John Dean

Julia Ellis
Linford Fernandes

Graham Foulkes

Kevin Fox

Linda Milnes

Rose Penfold

Anenta Ramakrishnan

Christian Subbe
Joanna Szram

Mark Temple

Louella Vaughan

Emma Vaux

Sheena Visram

Katharine Warburton 